\title{
Correction to: Papierstauraum: Bücher und Objekte in Katalogen
}

Jörn Münkner ${ }^{1}$

Published online: 31 October 2020

(C) Akadémiai Kiadó, Budapest, Hungary 2020

\section{Correction to: Neohelicon https://doi.org/10.1007/s11059-020-00545-y}

Due to an unfortunate turn of events this article was published without the six figures [Abb. 01] to [Abb. 06] mentioned in the article text. Please find in this correction document the six figures as such.

The original article has been corrected.

The original article can be found online at https://doi.org/10.1007/s11059-020-00545-y.

\section{Jörn Münkner}

muenkner@hab.de

1 Wolfenbüttel, Germany 
[Abb. 01]

\section{A T A L O US}

Variorum, infignism, varißsmorumqus

Theologicorum, Matbematicorum, $\mathrm{Hi}_{\text {- }} \mathrm{MF}$

foricorsm, ckedicorum of Chymicorsan, quàm crifcellaneorum,

Compatorum \& incompactorum

\section{I B R O R U M.}

Reverend. Dn. PETRISERRARII, Theologi P.M E T

Experientix. Dn. BENEDICTI BAHNSEN, Mathemat. P. M.

$$
\text { In quâvis Lingaâ }
$$

Hebraica, Grecâ, Latinat, Gallicia of realicat feripsoram, Als mede Hoogh en Nederduyt tche Boecken ,

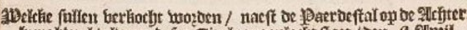

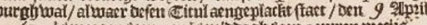

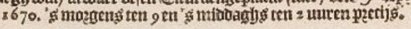

De Catalogen zijn te bekomen ten huyfe van

C K en D I R C K B O O M, 2Jocthuethuopers on

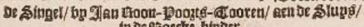

\section{कुष्हैं हैं}

A M S T E R O D A M $\mathrm{r}$,

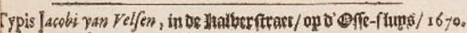




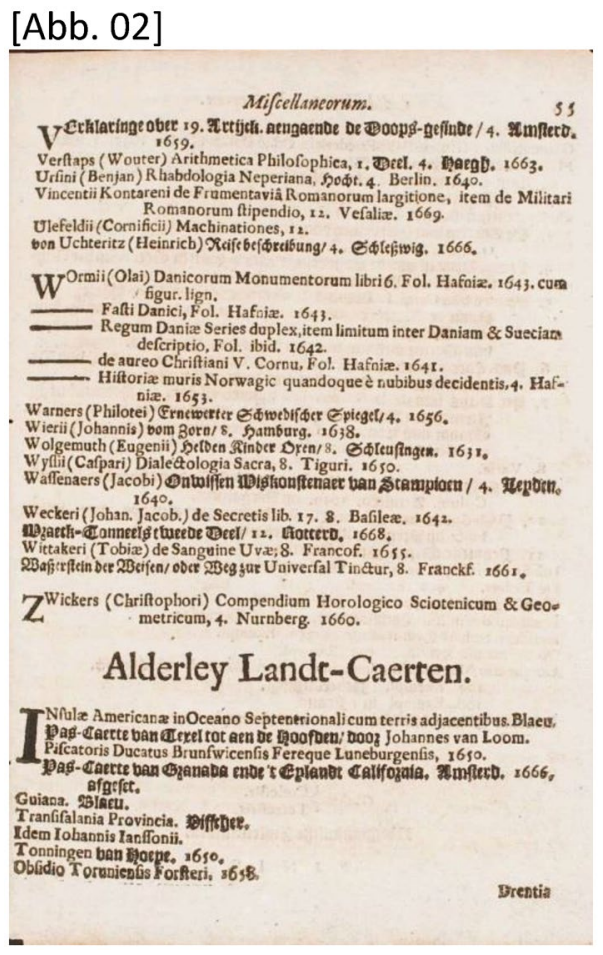




\section{[Abb. 03]}

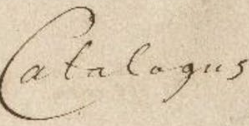

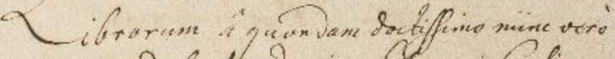

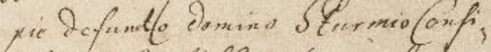

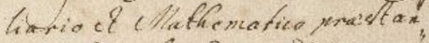

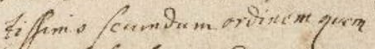

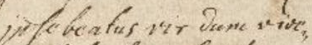
relclegit, enferiptus.

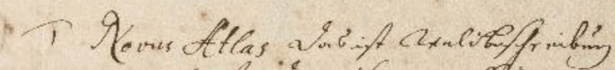

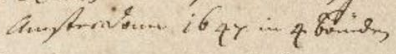

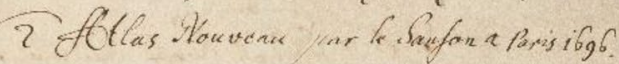

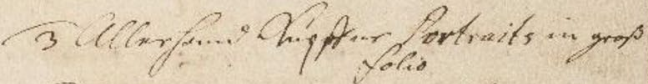

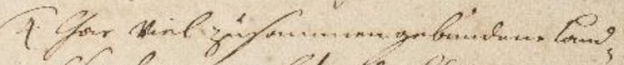

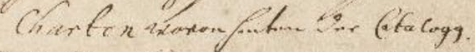

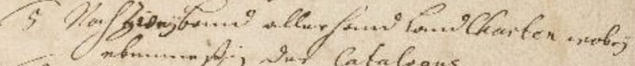

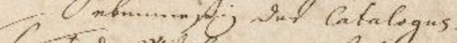

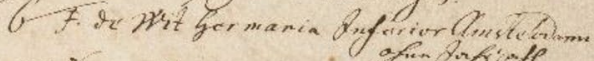

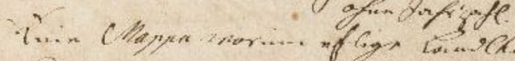

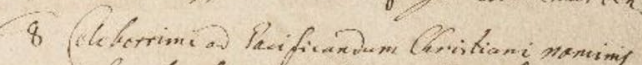

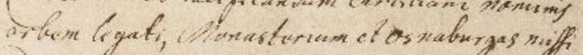

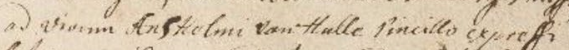

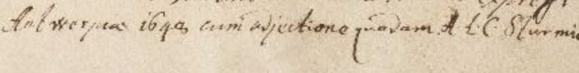




\section{[Abb. 04]}

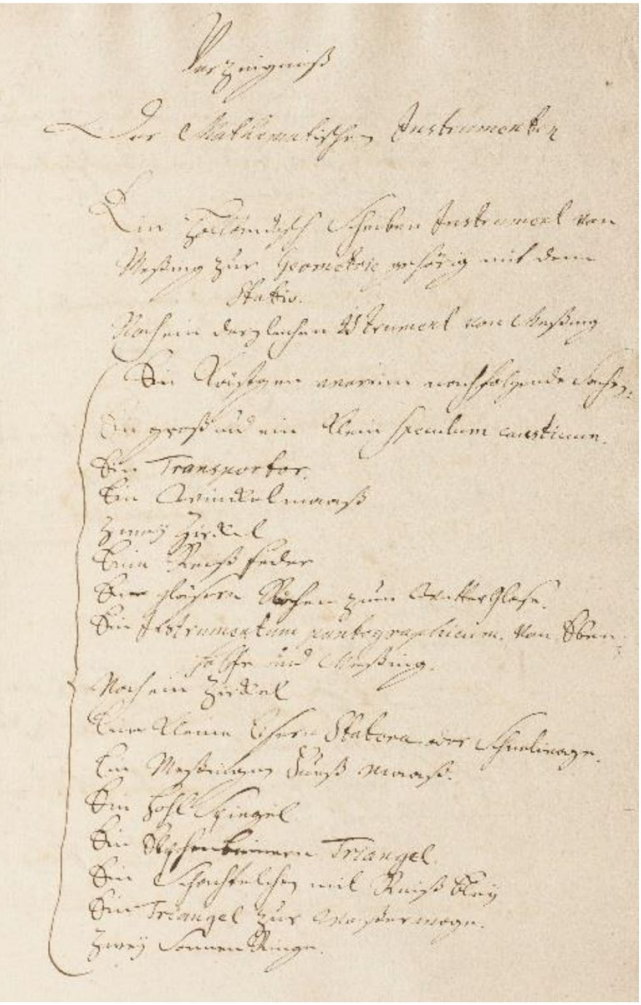




\section{[Abb. 05]}

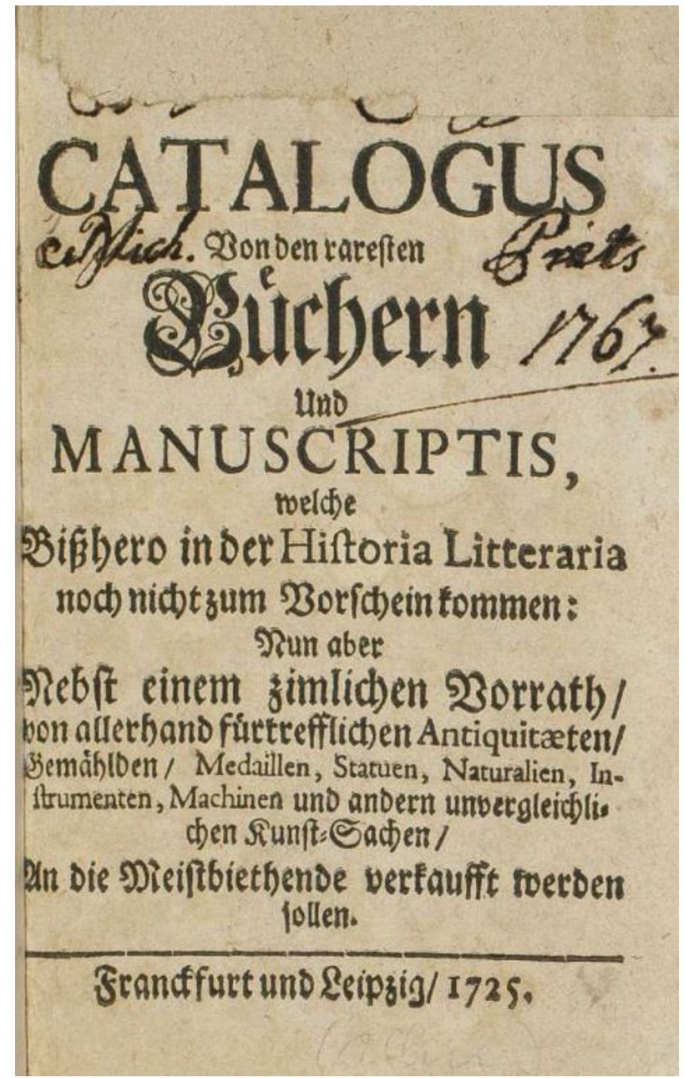




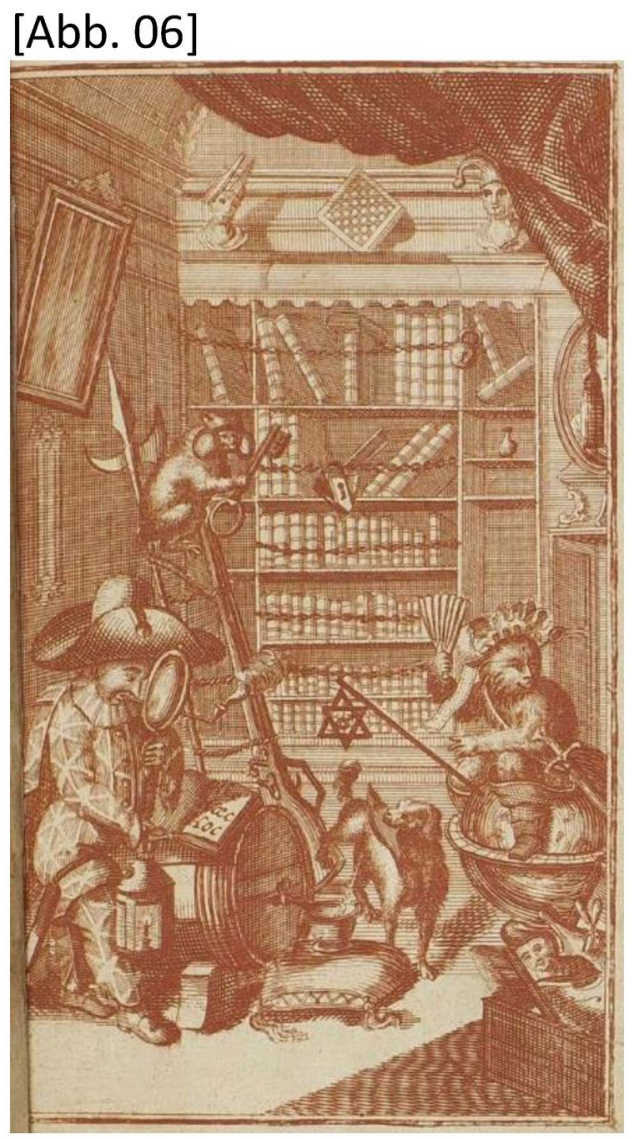

Publisher's Note Springer Nature remains neutral with regard to jurisdictional claims in published maps and institutional affiliations. 